\title{
Stanisław Kiczuk
}

\section{THE LOGIC OF CAUSAL PROPOSITIONS}

\begin{abstract}
The first part of the paper* outlines the development of causality in Greek philosophy. Some remarks are made on how some medieval philosophers approached to the problem. The paper shows also how modern philosophy understood causation. The paper inquires into the characteristics of causal relation as it is accepted in the domain of modern and recent physics.

In the second part of the paper one finds some remarks concerning the programme of construing a new system CI of logic of causal propositions. This system is adequate to the manner in which causality is presented in physics. The system CI is being construed to characterize the connective of relativistic conditionals ' $\rightsquigarrow$ ' by means of the methods of recent logic. This connective should be read as follows: 'if . .., then for that reason ...'. The arguments of the connective ' $\rightsquigarrow$ ' may be propositional formulas describing a particular event. The new system of non-classical logic is based on the classical propositional calculus, on the one of systems of temporal logic, and on a system ZI of logic of change. The findings concerning causation, as outlined in the first part of the paper, constitute descriptive semantics of the system CI presented in the second part of the paper. This system may play a positive role in the indirect justification of theorems in philosophy in a broad sense.
\end{abstract}

Keywords: causal logic; causal propositions; relativistic conditionals; time, change, causal relation

\section{Introduction}

In the philosophico-logical literature there already appeared studies which attempt to provide a system of the logic of causal propositions. However,

* The paper is a slightly modified version of the Polish article "System logiki zdań kauzalnych", firstly published in Roczniki Filozoficzne, 41 (1993), 1, pp. 27-71. 
the authors of those studies failed to consider the fact that different characteristics are ascribed to the causal relation in various types of knowledge and even in different scientific disciplines. It seems that one cannot build a formal system which would be adequate to the presentation of causality in each type of philosophy, in contemporary physics and in the humanities. In this paper we will be seeking a system of causal logic for physics. In order to construct such a system it is necessary to come up with an exhaustive characterization of the causal relation that contemporary physicist and philosopher of science refer to. However, the question of causality appeared first in the field of philosophy in a broad sense.

In the first part of the paper, on the basis of various studies, we shall provide a characterization of causality as it was presented in Greek philosophy, for there lie the origins of all the major problems concerning the concept of causation. We shall mention also some innovative approaches to the problem of causation that appeared in medieval philosophy. We will pay most attention to the understanding causation in modern and contemporary physics. The subject of the first part of the paper may be called a descriptive semantics of the systems of causal logic. This will be the basis for developing a system of the logic of causal propositions, that will provide us with a linguistic and inferential tools that may be employed, among other things, to show the formal structure of reasoning that is carried out in a language close to the natural one, in the language we talk about temporal relations, about change and causal relations understood in accordance with the findings of the physical sciences.

In the second part of the paper we will construct a system $\mathbf{C I}$ of the logic of causal propositions. This system will be based on the classical propositional calculus, on the system of the logic of temporal propositions "And Then" and on the system of the logic of change ZI. Each logical system that is an extension of the classical propositional calculus and includes the laws of the proper usage of the non-extensional connectives, may be regarded as a system facilitating an indirect justification of theorems in philosophy in a broad sense.

\section{Part 1. Philosophical remarks}

In the sphere of Mediterranean culture, philosophy was the first type of knowledge deserving the name of scientific knowledge. Nowadays, a 
knowledge is said to be scientific if it is at once creative, theoretical, specialistic, rationally justified, systematic (both in its form and content) and expressed in the intersubjectively understandable language. An important property of scientific cognition is its theoretical character. Science is meant to provide a rational explanation of the phenomena. The objective of science are truths interesting by themselves and not those which are of some practical value. The first scientific question, posed by the Greek philosophers of nature, is the question: what is the world made of (cf. [24, pp. 46-51])? This question involves one of the nuances of the concept of cause. For it embeds an aspiration to explain phenomena and to grasp the unity in the diversity of objects and facts, by reducing everything to a common origin, by showing the primary kind of bodies from which the nature evolved (cf. [9, p. 11]).

Slightly later, Greek philosophy began to seek in objects an element, which is not subjected to change. As A. Krokiewicz says, Anaximander, speaking about boundless primordial material that remains in eternal motion, taught Greeks to penetrate mentally the phenomenal surface into reality. Anaximenes - a ionic philosopher of nature - inquired explicitly the causes that explain the way the changes in nature occur and various states of the condensation of air emerge. He indicated as causes motion, inherent to the matter, as well as cold and heat. The separation of the matter and force took place under the influence of the Eleatic doctrine of the immutability and immobility of being as well as described by Heraclitus facts of experience and his thesis of the perpetual, albeit ordered, variability of things (cf. [36, vol. 1, pp. 23-54]). The ability of spontaneous qualitative transformation was no longer attributed to the matter. Empedocles understood the four elements - the four kinds of matter - as an inert mass. Thus the question why matter changes became well-founded. Two forces were presented as a cause of the change: Love, that binds the kinds of matter together, and Hate that separates the elements. Anaxagoras, introducing the concept of the rational soul of the world, interposed a new component of the problem of causality, that is the purpose of becoming.

The atomists tried to reveal a causal explanation of all phenomena. They are said to have made their view on the non-sensuous, essential reality dependent on sensory experience (cf. [24, p. 55]). They regarded motion as a property of matter, a property of atoms. It is everlasting, as atoms are everlasting, and consists in the changing the atoms' positions in space. All bodies in nature are made up of indivisible atoms, and 
all the attributes of atoms are quantitative. It needs to be emphasized that all the causes occurring in the world were treated by atomists as material and mechanical. For instance, according to them, the cause of the motion of the moon was a particular pressure of the air filling the universe, as W. Tatarkiewicz notices. It is worth adding that the atomists created the first Greek philosophical synthesis. This synthesis concerned a philosophy pertained with nature, a philosophy which was evolved in the initial period of Greeks' philosophy. The atomists, Democritus above all, comprehended the matter as the basic ground of being (cf. [36, vol. 1, pp. 54-62]). According to them, as T. Czeżowski noted, the causal explanation deals not only with the astronomical phenomena but specifies also what objects are made of and how they come to existence. However, observable objects and their sensory properties are only semblances that conceal the reality of atoms. Thus the causal explanation in a deeper sense consists in uncovering the true nature of those semblances. Therefore, already the atomists may be said to have been searching for the causes of the sensual world in a sphere more real than the sensorial one. Czeżowski calls the moment of uncovering the true nature of objects and their sensory properties the Democritus' other side of causal explanation.

A new and great philosophical synthesis, yet descended from a humanistic orientation in philosophy, was made at the beginning of the fourth century B.C. Human being and his artefacts became the object of study of the sophists and Socrates as well as their disciples. Socrates himself did not directly contribute anything to the question of causality, but he prepared the way for Plato to take up this question anew. Plato, like Socrates, was convinced of the existence of objective cognition. In formulating his new synthesis, Plato referred to philosophers who dealt with man, his thinking and conduct (cf. [36, vol. 1, pp. 108-132]). Plato however, as the ancient cosmologists, took the whole reality into consideration (cf. [9, pp. 22-25]). He considered permanent and changeless ideal being and soul to be the basis of being. The doctrines of the Plato's antecedents presented the real being as belonging to the material world. Plato's Ideas do not belong to this (i.e. material) world. They are neither psychical nor physical entities. It follows from their nature that they cannot go out of existence. They alone exist with a full and perfect existence. Things or phenomena come into being, pass out of being, and they are reflection of the world of Ideas, which are the final causes of any phenomena (cf. [9, p. 28]). The supreme idea is the idea of the good, this idea governs the world. As Czeżowski interprets it, all phenomena tend 
through the other ideas to the idea of the good. Apparently, the Idea of Good in Plato's philosophy does not differ from the Idea of being.

It is worth noting, as emphasizes Czeżowski, that apart from the relation of the end-goal which obtains between the phenomena and Ideas, there exists between them also some logical relation. Such a relation occurs also among the Ideas themselves, since Ideas are general concepts to which phenomena are subordinated. So there is a logical hierarchy with respect to the generality of ideas. According to Czeżowski, Plato identified the relation of the final cause and the logical relation of subordination occurring between a sense phenomena and the respective Idea. Plato's new concept of science originated from this identification of the logical and metaphysical (ontological) relation. According to Socrates, true knowledge was general and conceptual, while Plato, identifying the concept with the cause of phenomenon, defined true knowledge as a knowledge about the causes of phenomena (cf. [9, p. 29]). Plato's understanding of science was inherited by Aristotle and has persisted up to our days, though the concept of cause, as emphasizes Czeżowski, has undergone a considerable change.

Plato, as Tatarkiewicz points out, was also the philosopher who conferred a new meaning of the term soul. In Plato's approach the soul is neither a kind of matter, nor an extraterrestrial demon. It is something real, but not material. Stating it positively, the soul is what sets itself in motion, the source of motion, while matter itself is of its nature inert. The soul is an immortal element in man, whereas man, in Plato's view, is the soul governing the body.

Plato regarded material nature as the most mediocre kind of being. In his conception it was much less perfect than Ideas and souls. According to Plato, transient natural phenomena contain in themselves, so to say, existence and non-existence at the same time. He understood the non-existence, which is a concause of phenomena, as shapeless limitlessness. Czeżowski stresses that Plato's setting in opposition the existence given in Ideas against non-existence as the cause and concause of phenomena was an extremely important invention for the whole further history of the question of causality. The element of non-existence, passivity, an element possessing no shape became in the later transformations of Plato's doctrine synonymous with matter, which was attributed inertia and spatiality as its essential features (cf. [9, p. 31]). This was an abstract concept of matter, treated as something indefinite and imperfect. According to Tatarkiewicz, matter thus viewed was for Plato an 
abstract component of bodies, a non-divine element which brings about any imperfection and evil in the universe. Matter impede the universe being totally purposeful and in harmony with reason.

As it has been already mentioned, historians of philosophy emphasize that Plato, like Democritus, claimed that nothing could come to existence without a cause, and that the purpose of science is to discover causes. Purposefulness and a rational structure of the world made Plato believe in the existence of a deity who had rationally built the world (cf. [36, vol. 1, pp. 117-118]). Thus in Plato's conception the efficient cause of the whole material world was the divine builder - the Demiurge. This divine eternal builder made the world from the ever-existing matter, having as a paragon the eternal and imperishable Ideas. The details of the world's construction and its perfection in Plato's system may be explicated only by the notion of the final cause, and not by means of an accident or a mechanical necessity. The universe came into being when the Demiurge gave a concrete form to the indefinite matter. Summing up the above remarks, we may say that Plato mentioned three causes of the material world, i.e. the final, material and efficient causes. Plato's distinction of the world of sense phenomena from the world of non-sensuous Ideas as well as relating them together by the dependence relation became a paradigm for all further views that sought a cause for the existence of the world of sense phenomena in the extrasensory world.

In the literature of philosophy it is sometimes stated that Plato did not submit the concept of change and becoming to a thorough examination with the use of the acquired methods, for the empirical world could not be for him an object of knowledge. Aristotle overcame the negative attitude towards knowledge of the empirical world and the question of becoming turned to be the central issue of his philosophy. Consequently, the investigations concerning causality became extremely important. The Stagirite renounced his master's theory of being (cf. [36, vol. 1, pp. 133-157]), yet accepted the Platonic thesis that true knowledge is of general character. He maintained at the same time that only concrete objects are self-existent beings. Thus Aristotle broke with the Platonic doctrine of ideas. Matter and form become the constitutive elements of substance. In his approach, the form of an object is the content of the concept of this object. Each object possesses general properties, i.e., properties belonging to all objects of the same kind, and individual properties. What is not a form constitute a matter. Then the matter is what is unshaped, an indefinite foundation of phenomena 
and of any transformation that may come about in them. It is also a material from which substances have been created, and at the same time its multiplicity, diversity, and divisibility. The terms matter and form have become crucial in the conciliatory, yet extremely original system of Aristotle.

Sometimes Aristotle's form is said to be the same as Plato's Idea, with the only difference that the form is contained in things. It might be said that the pre-Platonic philosophers maintained that matter is a concrete substance. For Plato, only ideas were self-existent beings. According to Aristotle, neither matter nor the ideas, but concrete objects constituted by a matter and form exist independently. However, a form is the more important constitutive element of a concrete thing. The form in the Stagirite's conception - treated as the real counterpart of the concept - became the basic factor of both: cognition and being. Prime matter, which is completely lacking in form, is also unknowable. It should be added, following Tatarkiewicz, that in Aristotle's approach an accidental perception of a thing does not tell us what the thing really is. But what is contained in a concept is a property of an entire genus, is permanent and therefore essential. Bearing in mind the above remarks, form is also the essence of the thing, a set of its characteristic properties (cf. [9, p. 35]).

It is commonly stressed in the philosophical literature that Aristotle sought to explain the properties of things and to understand the thing itself by referring to the form of things or to their matter, or else to their efficient or final causes. Thus the Stagirite began to invoke the four principles of explanation, that is form, matter, efficient agent and purpose. These four kinds of causes co-exist when something comes into being (see [9, p. 34]). It is significant that the Greek philosopher treated the efficient cause as inherent in the form. Some historians of philosophy are of the opinion that Aristotle did not explain well the relation between the formal and efficient causes (see [9, p. 43]). At any rate, everything that comes into being has its efficient cause. According to Tatarkiewicz, the form in Aristotle was seen not only as a formal and ideal factor, but also as a force which acts purposefully and produces some effects. It followed that activity, action constitute the essence of being.

The authors writing about Aristotle unanimously emphasize that the Stagirite saw the frame of reality in concrete substances. Abstract relations were less important to him. Tatarkiewicz notes another important feature, that is that the Greek philosopher treated the qualitative 
properties of things as more essential than the quantitative ones, for the qualitative properties belonged, in his view, to the form. Thus Aristotle opposed to the quantitative treatment of phenomena preferred by the Pythagoreans and Plato. He explained the observed motion of bodies by their purposeful striving to the proper places. He treated the material world as eternal and spatially limited. The whole universe was for him a chain of events tied together by cause and purpose. All the elements in the universe are in principle of the same nature, except the first cause which is a totally independent, motionless, immutable, simple, immaterial, spiritual, unique and necessary being. The first cause-i.e., the spiritual, personal and transcendent to the world God of Aristotle-put the world in motion being the end-goal of the world. Aristotle's first cause may be seen also as a pure act, contrary to the prime matter; the pure act is the final cause of everything (see [9, p. 38]).

It should be recalled, as historians of philosophy presume, that according to Aristotle, the first cause acted directly only on one, external sphere of the world. The motion of the other superlunar spheres of the world was dependent on the entities resembling the first cause, but less perfect than it. In the celestial circle of the universe, where dominate the most perfect circular motion, matter was treated as ethereal. According to Aristotle, in the terrestrial sphere, placed in the very centre of the universe, dominated linear motion, and matter consisted of the four elements. Following Tatarkiewicz one can say that the celestial circle was treated as a circle of the eternal and changeless objects that was referred to by the Eleatic philosophers. The terrestrial circle was seen as a circle of changeable and transient objects, treated after the manner of Heraclitus. ${ }^{1}$ In the inception of each thing in the terrestrial circle there cooperate formal causes, that give shape to reality, and efficient causes which grant the proper impetus to this forming. Form is at the same time an end-goal, while efficient causes are bound with the material causes, due to the fact that they actualize the potentialities of matter

1 According to Aristotle, the terrestrial circle only through the action of stars, through the influence of the celestial circle may incorporate some valuable elements. Thus the Stagirite, developing theories concerning the opposition between the celestial and the terrestrial worlds, the influence of stars on the Earth, centrally situated in the Universe, as well as admitting the existence of the divine beings, that put into motion the spheres of the world, undoubtedly abandoned the Democritus' doctrine of a uniform structure of reality. He also renounced the astronomical system of Pythagoras, as the historians of science emphasize in particular. 
(cf. [9, p. 42]). Aristotle's doctrine of the four cases and the doctrine of the universe were the result of the approach initiated by Anaximander, and developed by the Pythagoreans, the Eleatics and Plato that consists of mental penetration through the phenomenal surface of thing to the core of its essential reality. It is worth noting that the metaphysics of the atomists was the least distant to the data of sense experience, for their view on extrasensory essential reality was dependent on the sense experience (cf. [24, p. 55]).

In the Hellenistic period the Stoics attempted to combine rationalism with materialism. They held that material nature, bodies, are the only real being. There was no room in their doctrine for the dualism of body and spirit, matter and life, God and the world. They worked out a monistic system, stating that the whole world is of uniformly construction, i.e., it is entirely material, animate and perfect (cf. [36, vol. 1, pp. 170-181]). The bodies, that make up the world, are constituted by the passive factor, i.e. matter, and the active factor - form. The latter, constituting the quality of bodies, was however taken as a more subtle sort of matter. The subtler matter permeates the passive matter. There are various degrees of intensity of the subtle matter (of the pneuma) in the passive matter, in bodies. As the active pneuma is inherent in all bodies, consequently there are no inert bodies. Thus, as Tatarkiewicz emphasizes, any piece of matter has in itself the source of motion and life. It can be argued that the Stoics advocated the materialistic and dynamic conception of the world. Sometimes they are even said to have driven the dualism of matter and form - in line with1 Democritus - into the framework of one causality (cf. [25, p. 307] and [9, p. 45]). Their materialism, however was not mechanistic. For the mechanistic atomists accepted the thesis that motion, consisting in the change of place in space, should be treated as a common property of uniform atoms. And each atom possesses, according to Democritus, its own primal movement, thus it may collide on its path with other atoms. Ultimately, all phenomena are causally conditioned by those primal motions of atoms. Then the mechanistic atomists tried to explain everything in the world by means of the concept of the efficient cause. Moreover, they sought only the more proximate causes. They did not investigate into who set matter in motion at the beginning, i.e., they did not ask about the first efficient cause.

The Stoics, having assumed that there is no matter without form, nor form without matter, but only things and bodies which have been 
constituted by matter and form, hold that things, bodies and substances are the causes. Czeżowski remarks that causes, as conceived by the thinkers of the cosmological period of Greek philosophy, may be called material, the causes of Plato's and Aristotle's conceptions may be called ideal or formal, whereas the causes according to the Stoics may be called substantial. In the Stoics' view, only quantitative or qualitative changes in other bodies may be effects of causes. However, those changes - or simply properties of other bodies - themselves are not bodies. A property of a body is what can be predicated of it. Consequently, in the Stoics' view, the causes are corporeal, while effects as the properties of bodies are incorporeal (cf. [9, p. 60]). Krokiewicz calls these effects incorporeal verbal values (cf. [25, p. 308]). The Stoics conceived the causal relationships as a relationship of efficient causality, as an action among bodies, consisting in producing an effect. Czeżowski calls it a realist conception of causation. Historians of philosophy also emphasize that Stoics understood the action not only mechanically, as a strain or stroke, but also qualitatively. Czeżowski accentuate in the Stoics conception the element of a temporal succession between cause and effect, as according to them, nothing may happen without an antecedent cause. The element of temporal succession occurred neither in the conception of the material cause, nor in the ideal approach to causality.

As the constitutive element of each body is the active pneuma-form, then the efficient causes, according to Stoics, are everywhere of the same nature. The pneuma does not act blindly and mechanically, but purposefully. Purposefulness interpreted by the Stoics as the action of supernatural or spiritual forces. It is a natural property of the pneuma. Pneuma, also called reason, was for the Stoics a cosmic force, and not a supernatural demon. This cosmic reason rules the world and establishes law that binds everything in the world. The world was not conceived as an aggregate of separate parts, but as an organic body, which is alive, rational, purposeful, uniform and subordinate to one law. The Stoics attributed to the world, precisely to the pneuma, a divine nature, that is they claimed that the world is unlimited, eternal and infinite (cf. [36, vol. 1, p. 173]). The Stoics view of the world was hylozoistic, finalistic and pantheistic. The Epicureans also devoted much attention to the question of causality in the Hellenistic period. They reduced, like Stoics, all causal relations to the influence of some body on another. And the influence itself was understood by them mechanistically. Epicurus' theory of nature was materialistic and called upon Democritus' view. Apart from the substantial- 
ist understanding of cause and realistic approach to the causal relation, which in a way is included in the Epicurean system, one may also say that the Epicureans, just as the Stoics, grasped the temporal posteriority of effect to cause (cf. [9, p. 61]). It must be added that it was Epicurus that denied the view that definite and specific effects always correspond to a given cause. He is said to have introduced into his system a number of indeterministic hypotheses (cf. [9, p. 50]), along with the hypotheses of atomism and mechanistic visions of the world. He introduced also the concept of an accidental event as that which does not possess any cause.

Stoicism in many questions differed fundamentally from Epicureanism. Those philosophical systems, as has been stated, were similar in their understanding of causality. Czeżowski notices that the substantialist approach to causality and the realistic conception of the causal relation may be regarded as the characteristic features of the whole period of Hellenistic philosophy. He emphasizes also, that the Hellenistic conception of the causal relation constitutes the third stage in the evolution of the question of causality in ancient philosophy. This conception is an ultimate achievement of this philosophy with respect to the understanding of the causal relation.

Researchers that investigate the question of causality observe that the substantialistic and realistic standpoint on the question of causality was attacked by the Skeptics at the close of ancient philosophy. They opposed Hellenistic substantialism and realism with their causal phenomenalism. The Skeptics left unquestioned only those judgments concerning phenomena, that provide us with knowledge of our own states and feelings. Unlike phenomena themselves, they thought that the causes of phenomena are unknown to man. They treated judgments concerning causes as unreliable. According to Czeżowski, Sextus Empiricus claimed that bodies could neither act nor be passively subject to actions. The terms cause, effect are - according to the ancient authors - relational terms. By means of them we express our knowledge of conceptions of objects in our minds, but not a knowledge about the objects in themselves. In Sextus' view, there is no reality of causes and effects, except in the human thoughts wherein they are appended to the presentations of things (cf. [9, p. 64]). Therefore one cannot accept any statements regarding the causal relation among things. The notion of the causal relation is a product of the activity of the human mind.

Sextus' position on causality was rather isolated in Greek philosophy. The ancient philosophers drew a clear distinction between the succession 
of equal-rank elements and the causal relation. Krokiewicz observes that already in antiquity the Stoics were occasionally accused of confusing the relationship of succession of events with the causal relation. It is extremely important that in the ancients' view cause and effect were beings of different kinds. For Greek thinkers the efficient cause was always more valuable than effect (cf. [25, p. 310]). In the effect the cause was somehow degenerated: this is indicated - according to the authors - by pairs of theoretically important terms such as atom - sensible object, idea - substance, acting body - incorporeal verbal value. It is also important to note that in antiquity the question of causality was treated as a metaphysical question. Not earlier than in the Skeptic thought, some ideas appeared that were elaborated in the subsequent ages and made the question of causality the matter of epistemology, wherein various kinds of cognition are analyzed.

It may be added that efficient causality, as the ancients understood it, took the form of neo-Platonic emanation. According to Plotinus, Krokiewicz notes, the series of causes go from the arch-divine One, through the ideas of mind and the rational factors of the soul, to the phenomena of the sensible world. In view of some historians of philosophy the neoPlatonic spiritual concept of cause appeared to overcome the Skeptics' objections to the Stoic material conception of the causal relation.

In Greek philosophy of the cosmological period, the period of dominating humanistic philosophy, the period of the ancient philosophical systems and the subsequent period of the ancient philosophical schools much attention was devoted to the question of causality and the question of particular causes. The ancient thinkers, with respect to the question of causality, asked consecutively about the matter of a thing (of what? how?), about the form or reason, and finally about the acting bodies (cf. [9, p. 65]). Aristotle defined scientific knowledge as a general and certain cognition which deals with the essences of things and explains them by causes. The Stagirite, as it has been already mentioned, admitted four kinds of causes: two internal and two external ones. The efficient cause was among the latter. The conception of the efficient cause has undergone a considerable modification over the ages, even though verbal formulations may have remained unchanged. This was due to a different way of understanding being itself. One should consider here a theory of Thomas Aquinas, one of the classics of metaphysics. He is sometimes said to have headed philosophy in the thirteenth century in a new direction of realism. In Thomas' philosophy, there appeared a 
question of explaining that things are when they do not have to exist, and that they are such as they are. It can be said that then, when the importance of the existing concrete was noticed along with a reflection on its being caused. Such oriented philosophical consideration, starting from relatively poor empirical data, reveals that each contingent being is composed of essence and existence. The thesis of this constitutive factors of being is completely beyond the range of the theoretical capacity of the thesis of the modern natural science.

According to Aristotle and Greek philosophers, the cosmos as a whole has always existed, but it was subject to various changes. Efficient causation always concerns beings that already exists. The definition of the efficient cause did not change from Aristotle's works to Thomas'. The efficient cause was still considered as a first source of real motion. However, this causation was understood completely differently. Efficient causality became connected with the existential side of the being. The motion was interpreted as to include the coming into existence of being itself, and not merely the generation of a new form in pre-existent matter. In this conception, it was existence, and not form, which was the decisive factor for being. In the order of being as existing there is only one main efficient cause, and all others are instrumental. The main cause is the Absolute whose principal way of effecting is creation (cf. [23, pp. 473-474]). In the philosophy initiated by Thomas Aquinas secondary causes could be primary causes in some other aspects than the existential one. In this aspect they can employ the efficient and instrumental causes. M. A. Krąpiec remarks that we find many varieties of so-called secondary causes. Secondary causes are such as beings are. An important difference is the difference between the efficient action of animate, especially rational, causes and the necessary action of irrational and inanimate causes. In this current of thought it is emphasized also that among all distinctions in the order of efficient causes the most important is the distinction between the efficient cause as such and the efficient-instrumental cause, which - as Kraciec says - acts by virtue of a movement imparted to it by the main efficient cause.

The action of every self-existent being, excepting the Absolute, is performed by mediation of powers of action. If the efficient action of a cause through the powers is performed in the context of matter, than it occurs always in time cf. [23, p. 475]). In the material world one can speak about the ontic and temporal priority of the cause in relation to its effect. 
Analyses of the cause of being in classical philosophy, relying on Thomas Aquinas' approach, allow us to state the efficient causation may be examined from several points of view. If we examine it with respect to being as existing, that is from the point of view of the general philosophical theory of being, then we must affirm the existence of the First Being whose essence is existence, and the existence of beings composed of essence and existence. The latter beings are derived from the Absolute and may be called the created world. The beings made up of essence and existence may also perform efficient causation, as we have already mentioned, but only in the dependence of the Absolute. Each effect generated by secondary causes is, in the light of the general theory of being, an unnecessary being. Secondary causes are not the reason for the existence of the effect but they are its reason with respect to the circumstances of such and not another way of being (cf. [23, p. 484]). Here the philosophical, metaphysical principle of efficient causation may also be considered. It states that a being that does not contain in itself the reason for its existence has a reason for existence beyond itself. In other words, we can say that each contingent being has an efficient cause (cf. [32, p. 77] and [21]).

It should be emphasized that the Aristotelian conception of the four causes, although modified, went virtually unquestioned for more than a millennium and a half. The Skeptics, as we have mentioned before, were just a minor exception. It was William of Ockham who made an important effort to undermine the traditional formulation of the principle of causality. He was also the author of new ideas in theology, philosophy, cosmology, and physics. Ockham came up with a substantive criticism of Aristotle's physics which was grounded on the theory of movement (cf. [36, vol. 1, pp. 403-417]). Ockam's followers were engaged in general philosophical questions and theological questions. Other Ockhamists dealt with the natural history. Though they still used peripatetic terminology, they took issue with Aristotle's doctrine. The key terms of Aristotle's philosophy, such as matter and form, were gradually being deprived of their philosophical and metaphysical content (cf. [34, p. 34]). The historians of philosophy notice that Buridan began to speak about a force called impetus, which was used to explain the self-persistence of a motion after it had been initiated. Buridan claimed that this force is proportional to the speed with which a body is moved and to the quantity of matter the body contains. The application of the theory of impetus to the movements of the cosmos permitted the elimination of 
Aristotle's aforementioned doctrines, in which it was assumed that the stars are moved by divine creatures. Now one could start treating the celestial and terrestrial movements as being subordinate to one and same mechanics. Tatarkiewicz cites historians of science to the effect that the theory of impetus formulated by the Ockhamists in the 14th century is the point at which contemporary science parts ways from ancient science. Ockhamists ideas started in Oxford and Paris and were popularized in Vienna, Prague and Cracow. These ideas persisted in Italy until the times of Galileo.

At times it is claimed that the modern variety of science was constituted by the change in the concept of experience (cf. [1, pp. 69-71]). The directly perceived objects of the world began to be distinguished from the objects with which we deal only through their instrumental representations, through instrumental readings. According to this distinction, there are visible objects and observable objects. Prior to that, the observable object had not constituted any point of departure in science, they did not exist as the objects of experience.

Modern scholars and physicists have admitted a limited field of research. This was due to their postulate that only statements verified, or at least verifiable by experience may be accepted (cf. [11, p. 74]). Those statements must concern some properties of bodies, and need to be formulated in the language of mathematics. All the adopted restrictions permit to cope with the world only in certain ideal situations. Due to the need for another type of theoretical knowledge, Galileo and Isaac Newton invented totally new concepts, such as 'location', 'time', 'velocity', 'mass', 'force'. Those concepts are sometimes said to be the ingenious modifications of the categories of the previous philosophy of nature. The fact is that all the aspects of reality that cannot be grasped by these concepts have been left aside in scientific investigations. In the centuries that followed, some further pivotal concepts concerning the quantitative aspect of reality were introduced in the physical theories other than mechanics. Because of the restricted - in comparison to that of Greek philosophy - field of investigation in modern science, of the change of the concept of experience and the different theoretical weightiness of the statements of modern physics and the statements of philosophy, causality undoubtedly is to be understood differently in modern natural science and in the Greek philosophy or the philosophy of St Thomas Aquinas. Physics grasps only the quantitatively measureable aspect of the object under study. The physicist does not raise any questions concerning, for 
example, the being as existing (cf. [32, p. 48]). Actually, as early as the end of the 15th century it was debated in Padua whether causality should be understood in quantitative, rather than qualitative manner (cf. [34, p. 46]). Moreover, the problem of causality was not neglected by the commonly recognized founders of modern natural science whose chief works appeared in the 17th century (cf. [40, vol. 1, pp. 205-210]). For example, Galileo, who desisted from penetrating into the true nature of things and contented himself with the study of laws concerning phenomena, and not the essence of things) was principally interested in studying the laws concerning the causal relation. Newton, like Galileo, was interested in establishing what phenomena are interrelated by the causal relations. However, since the founders of the modern natural science adopted the aforementioned limitation of the field of investigation, they had to eliminate from the scope of science the transcendent causes, evoking the events available to experience. They also abandoned the interest in the interior causes and the final cause (cf. [28, p. 91]). The only relevant cause became the efficient cause. In recent centuries various attempts have been made to define what the efficient cause is. Inter alia, the search for a strict formulation of the so-called principle of causality served and still serve this purpose.

Thus, there is no doubt that the founders of modern natural science borrowed from philosophy the idea to search for the causal relations. However, since events became the object of science, neither the Aristotelian nor Thomistic concept of cause could be adopted. The discussion of the qualitative essences of things, of the reasons for the effect in the aspect of its existence was desisted and only the quantitative aspect of event-effects was considered. Attention was paid in turn to the changes in the physical properties belonging to the studied systems, singled out either factually or mentally. The cognitive grasp and linguistic formulation in this respect of the relation between the cause and effect must be somewhat different than the formulation of the principle of the efficient cause in the classical philosophy of being as that which exists. The latter, in the classical philosophy is necessary and objective, and cannot be rejected without falling into contradiction with the initial facts. ${ }^{2}$

${ }^{2}$ It should be stressed that for I. Newton the scientific cognition, as well as the theses of his philosophy are objective, necessary and certain. It was D. Hume who turned attention to the hypothetical character of the theorems concerning reality, that grasp it in its content aspect. But the thesis that within the particular real sciences 
In the most recent literature devoted to the philosophy of science it is occasionally stated that modern science has abandoned any hope of discovering a single law of nature according to which all the events in the world would occur (cf. [2, pp. 49-54]). So the regularities in the various separate fragments of reality have begun to be studied. S. Amsterdamski remarks that the goal of science is not to prove the existence of the natural order, but to discover in what it consists in the various fragments of reality. The ontological assumption that there exists a natural order which may have a causal character is - according to Amsterdamskithe initial assumption of all contemporary scientific knowledge. Similar theses may be found in treatises of other contemporary philosophers of science (cf. [40, vol. 2, p. 235]) Science may only change the current conceptions of the natural order, taking into account new facts, new experimental data, but it needs to assume that some order exists. It is also worth mentioning that, as the philosophers of science often stress, that apart from the aforementioned ontological assumption the scholar makes also an epistemological assumption that it is possible to get to know this natural order.

One cannot avoid recalling here that in the history of human thought there were people who opposed treating the causal connection as an ontological category. The Skeptics belonged to this group. We have already mentioned also that in the 14th century Ockham attempted to undermine the principle of causality in its traditional formulation. Notwithstanding, the founders of modern science searched for the causes of various types of observable events. However, the conception of cause as something external to the object under study was subjected to criticism by David Hume. He criticized the principle of causality as the principle of necessary connection (cf. [14, p. 253-254]). His criticism constituted the drawing of consequences from the empiristic doctrine of his predecessors (cf. [41, p. 43]). John Locke's thesis that man knows as much, as he has experienced, led Hume to accept the opinion that the category of causal conditioning is merely a subject-cognitive category. The causal relation cannot be known as an attribute of a thing, for it is not a relation between things or events, but a relation between their representations in our minds (cf. [9, p. 9]). According to Hume, one may empirically assert only a constant succession or coexistence of what

no view can be asserted definitively and absolutely, became widespread as late as the epoch-making discoveries made by W. K. Roentgen and A. Einstein. 
is called cause, and that what is called effect, but not the bringing out the effect by the cause. There is no contradiction in the supposition that although a certain event has had a certain effect, a similar event might have a different effect. Experience and inference play no role in the extrapolation of past and present events on to the future, but habits do play a role. The constant repetition of certain connections does not change anything in the nature of those connections, but it does change our attitude towards them. This repetition produces in our minds the disposition to expect further repetitions (cf. [36, vol. 2, p. 157]).

Hume's ideas concerning causality was shared by the positivists of the 19th century. Bertrand Russell generally subscribed to Hume's explanation of the causal relation (cf. [40, vol. 2, p. 181]). Under the overwhelming influence of Bertrand Russell remained the leader of a Vienne Circle, Moritz Schlick, and other positivists logicians. Friedrich Waismann wrote that the year 1927 marked the burial of causality in contemporary science (cf. [40, vol. 2, pp. 163, 181]).

It is to be emphasized that apart from the authors faithful to Hume's standpoints there were also philosophers who did not accept his analysis of the causal relation. For instance, as early as the 18th century Immanuel Kant gave a new and unique solution of the questions discussed by the English philosopher. According to the German thinker, the principle of causality is not a result of experience, but its presupposition. It is due to causality that experience is possible. Kant subjectivized time, space and causality. He treated them as common and necessary forms of the mind. In the beginning of the 20th century Hume, apart from followers, had many influential critics of his concept of causality. Among the latter there were always the Kantists, neo-Kantists, Thomists and followers of other scholastic philosophies. Also the philosophers of the linguistic and analytical orientations were not missing among the critics. In the first half of the 20th century, the philosophy of Henri Bergson arose in response to the various schools having in a way Hume as their patron. Bergson's philosophy professed an affirmation of becoming and the dynamic causality connected with becoming as the basis for a proper understanding of the physical world. According to the philosophers of science, Alfred North Whitehead was the principle author in the restoration of causal efficacy as the primal and explanatory factor in physical science (cf. [40, vol. 2, pp. 217-219]). It is important that Whitehead's positions on the causal relation originated from the analyses of the weak points of Hume's epistemology. Contemporary philosophers of science, 
such as M. Bunge and R. Harré (cf. [40, vol. 2, p. 229]), who deal explicitly with the problems of causality and scientific explanation, point out the inadequacy of Hume's and the positivists' explanations of causality.

The above cursory remarks concerning various conceptions of causality indicate that the terms of causality, cause are theoretical terms of various systems and philosophical trends, and in particular, they are theoretical terms of classical philosophy. These expressions appear in the philosophy of science and in the languages of the particular sciences, but in each case according to the meaning proper to the discipline. The expression "principle of causality" often appears in the texts on the philosophy of science. It is sometimes used in reference to the physical principle of causality. The latter is to be a cognitive expression of each efficient causation, and is to characterize as accurately as possible each causal relation in the key discipline for all natural sciences. The cause, the causal relation, characterized by the various formulations of principles of causality within the contemporary philosophy of science, are understood in a different way than it was understood in ancient philosophy, even in its final period. According to the ancient formulations (excepting the Skeptics), and according to classical medieval philosophy, cause and effect were not mutually homogenous. As we have mentioned, the cause, even an efficient cause, was always treated as something more perfect than effect. The modern conception of the causal relation, as Czeżowski has observed, is characterized by the fact that cause and effect are treated as uniform elements, as entities of the same kind. Inquiring about the cause of what happened, the modern researcher mean an antecedent event. Because of this uniformity, whereby the causes of empirical events are reduced to the sphere of empirical world, the problem of causal explanation has lost its speculative character (cf. [9, p. 66]). At the same time, it has become a problem of the particular sciences and of the philosophy of those sciences. ${ }^{3}$

In physics one may say that the causal relation, i.e., the relation between cause and effect, consists in the fact that the cause produces or makes its effect. The expression "causal relation" occurs in the natural sciences most frequently in this sense. However, factors or objects may have different types of influence on one another. Mechanics speaks of a

3 There are contemporary scholars who, assuming the pluralism of the types of theoretical knowledge, allow for various ways of causal explanation, including causal explanation akin to the explanation made by the ancient philosophers. 
one-sided exertion of force of one object on the other. Thermodynamics speaks of a heat transfer from one body to another. Generally, at the present moment, we may speak of gravitational, electromagnetic and nuclear forces. It is recognized that the fastest possible force is the light signal. Although the content of the thesis that these energy transactions have a real character has been subject to modification, this thesis is still an inalienable component of the natural sciences (cf. [16]).

Each of the reactions causing changes in the physical world consists in a transfer of energy. The change of state of a body or a system expending energy may be called a phenomenon or event. ${ }^{4}$ The relation between bodies which occurs when a stream of energy flows between them (either in one or both directions) should be distinguished from the causal relation. The latter, in its most elementary cases, consists in a one-sided transfer of energy form body $A$ to body $B .{ }^{5}$ The cause is the transfer of energy by body $A$, and the effect is the gaining of energy by body $B$. This is a common feature of all the causes and effects of the physical type. However, it is not always the case that in the causal relation of the energetic type the researcher is interested exclusively in the fact of the transfer of a portion of energy from one body to the other (cf. [22, pp. 212-217]). W. Krajewski states that when we speak about event-effect, we are most often interested not only in the fact that body $B$ is acquiring energy, or in what type of energy, among all the types recognized by physics, it gains. For instance, in the case when a billiard ball hits freely lying ball, the other ball will be set in motion. The cause here is the transfer of kinetic energy which, as Krajewski stresses, passes to the second ball. In the case when the other ball is fixed we can say that the kinetic energy is converted into the heat energy. One may, however, point out, as Krajewski remarks, other changing attributes of the fixed ball. It may get deformed; it may be broken in two or more pieces. All these are different effects, yet each time we deal with a conversion of the mechanic energy into the heat energy, and it may happen that the same amount of energy is transferred.

In the above instance of the collision of two balls, the effect may be treated in various ways. According to Krajewski, one may variously

${ }^{4}$ Cf. [10, pp. 22-23], [42, pp.28-29] and [33, p. 71]. In the present paper there will not be any distinction between the meanings of the terms event and phenomenon.

${ }^{5}$ Cf. [22, p. 181]. Interaction may be considered the cause of changes in the system, in particular the cause of its differentiation, development, yet rather in the sphere of social phenomena. 
treat the cause, too. In this example, instead of energy, one may pinpoint such a parameter as momentum. With this approach the cause would be a loss of momentum by the first ball, and the effect would have to be taken the gaining of momentum by the other ball. It may generally be said, as Krajewski remarks, that regarding as scales of cause and effect the changes of various parameters of the bearer of cause and effect we gain for the same causal effect diverse forms of mathematical relation between cause and effect.

It may justifiably be said that the natural sciences discover the dynamic relations among events at the basis of several regular sequences in nature. In the world then there is something more than merely constant succession of events. We deal here with real interactions among objects. In the formulation, and especially in the understanding of the principle of causality, which the natural scientist presupposes before embarking on the scientific research, the moment of efficiency, the moment of a dynamic relation among events, the moment of the transfer of energy cannot be omitted. ${ }^{6}$ The schematic formulation of this principle should be endowed with a sense which takes into account the results of contemporary physics in its final point, and not only its initial experimental basis.

The analyses of M. Bunge, due to their versatility, seem to may serve as a basis of investigations for an adequate formulation of the principle of causality in physics. According to Bunge, the laws of science and the principles of scientific ontology (here he puts the principle of causality) should be expressed in the form of conditionals. ${ }^{7}$ After a long discussion the American author comes up with the following formulation of the principle of causality:

(a) Always (and only) if $C$ occurs, occurs $E$, caused by $C$.

The above formulation expresses the constant correlation between associated events and states that the effects are occasioned by causes. ${ }^{8}$

6 The principle of physical causality is sometimes called a philosophical principle, a valuable signpost of scientific research, which like other sign preserves its value within limited ranges. It is a general, ontological hypothesis, of great heuristic value and that suggests that in some domains it strictly corresponds to reality. See $[6$, pp. 158, 223, 334-335].

7 As regards the laws of science it is an approach commonly accepted by the methodologists of science. See, for instance, [30, p. 47].

8 It is not the only formulation of the physical principle of causality known in literature. 
Then, efficiency fundamentally determines the asymmetry of the causal relation. Formulation (a) states implicitly the following properties of the causal relation: its conditionality, unambiguity, one-sided dependence of effect on cause, constancy and that the effect is brought about by a cause. The American author believes the scheme defining the relation of causality as a constant and uniform generation to be an adequate formulation of the principle of causality. He does not claim, however, that the causal relation is thereby grasped in its full richness.

Bunge's statements lack precision in some points. For instance, his statements regarding the relation between what we call cause and the set of real conditions, making up the sufficient (or both sufficient an indispensable) condition of the occurrence of effect are not sufficiently clear. The causal relation is not a relation of the sufficient condition. The cause which is an event, an acting, efficient factor, produces the effect, and the conditions merely makes it possible. According to Krajewski, a sufficient isolation of the system belongs to these conditions; the isolation prevents any external influence that would make the effect impossible. It may be said that the cause is a component of the sufficient condition. It is striking that Bunge did not take into account the time precedence of cause to the effect, that was already considered by the Stoics, as we mentioned. Apparently Bunge in this point betrayed, in a way, his methodological postulate, i.e., to seek such a formulation of the principle of causality which would draw insights from the theories of physics. Contemporary physics studies various properties of time, including the properties of temporal relations. ${ }^{9}$ The theory of relativity ${ }^{10}$ is currently the leading theory in the main discipline of the natural sciences. Thus any attempts to formulate and understand the physical principle of causality cannot fail to include the insights derived from Einstein's theory. It must be assumed that in the causal relation the stream of energy flows from the event-cause, that precedes the event-effect by any time interval, to the bearer of the effect. This stream of energy may be transmitted through the intermediate links.

As we have mentioned, physics employs the term interaction to indicate the transfer of energy in time and space. Classical mechanics implicitly assumed that there exist interactions propagating with infi-

${ }^{9}$ The question of the physical theory of time is taken up by Z. Augustynek in [3, p. 14].

10 We mean here Einstein's both theories of relativity. 
nite speed. The theories of the electromagnetic field have somewhat modified this view. The special theory of relativity assumes that there exists a maximum speed of the propagation of interactions in nature. In relativistic physics it is presupposed that the causal relation is identical or at least coextensive with the relation of interaction (cf. [3, p. 173]). Since there exists a border speed of the transfer of energy, there exists also a border speed of the propagation of causal connection. Identifying the causal relation with the physical interaction facilitates to realize some further properties of the causal relation. These will be the same as the formal properties of interactions with which we deal in the world of physics. Each such interaction is irreflexive, transitive ${ }^{11}$ and asymmetric.

Relativistic physics, especially the special theory of relativity, examines also the properties of temporal relations with regard to the study of the electromagnetic interactions, propagating at the speed of light, and of interaction in general. One of the theorems of the special theory of relativity states that if one event interacts electromagnetically with another, then the first is absolutely prior to the second (cf. [26, pp. 34-36]).

Thus from the point of view of the theory of relativity, if there occurs a causal relation between two events, then the temporal succession of these events will be the same in various frames of reference. Therefore the temporal relation of the two events of this kind is absolute. If there occurs no causal relation between two events, then it cannot happen that what occurs prior to one observer, occurs as posterior to another observer. It seems that G. H. von Wright does not distinguish (in the theory of relativity) the properties of temporal relations occurring between causally related events from the properties of those occurring

11 The authors who advocate the conception of the temporal contiguity of cause and effect cannot accept the transitive character of the causal relation. Because if an event $A_{1}$, lasting from the moment $t_{1}$ to $t_{2}$ is the cause of event $A_{2}$, lasting from $t_{2}$ to $t_{3}$, and the latter is the cause of the event $A_{3}$, lasting from $t_{3}$ to $t_{4}$, then $A_{1}$ cannot be a cause of $A_{3}$, for they are not temporally contiguous. Yet the pairs of events, as viewed by the theory of relativity, are always separated in time and space. That is the standpoint of contemporary physics. It is easy to notice that the authors assuming the theory of the temporal contiguity of cause and effect, treat cause as a sufficient condition of effect (Gawecki mentions a necessary and sufficient condition). As we mentioned, it seems that there is no need to identify cause with the sufficient condition of effect. The cause may be an event preceding the event-effect, if the stream of energy flows from the former to the latter, even when it happen through a series of intermediate links. Those links may be common bodies or physical fields. The cause, however, brings out an effect under determined conditions. One of them is the isolation of the system; the isolation prevents the invasion of interactions that would interfere with the effect. 
between the events that are not causally related. His thesis about the branched character of time in relativistic physics and related statements is an evidence of that (cf. [39, p. 211]).

It must be stated that the moment of priority of cause in relation to effect cannot be ignored in the formulation or understanding of the principle of causality in physics.

The causal bond in various kinds of philosophy is said to be necessary. Thus it should be asked whether necessary is the causal relation, determined by the physical principle of causality. It has already been emphasized that the principle of causality tacitly assumed by the physicists prior to research, differs from the principle of causality of metaphysics, the discipline that states, inter alia, that a being, considered as existing, may be necessary, for instance in the aspect of essence (cf. [15]). It is not easy to answer the question in what the necessity of causal relation consists in physics. According to Bunge, the necessity of causal relation is constituted by its constancy and uniformity. Krajewski identifies the causal relation with constant, exceptionless succession of events. It seems that most authors interpret the necessity of causal relation in a way that excludes the possibility that the existence of a cause and proper conditions may at any time or place entail the nonexistence of the effect. It is also precluded that the occurrence of the cause and required conditions whenever and anywhere brings out the effect only in a certain percentage of instances. Thus in any domain of physics, whenever occurs cause $C$, then constantly the effect $E$ occurs. Therefore, physicist qua physicist postulates the repeatability of the causal relations.

There seem to be nothing that stands in the way of ascribing necessity to causal relations in physics, as most authors do. It must be assumed that the necessity of the causal relation in physics is somehow presupposed, as presupposed are the principles stating that the elements in nature and systems of these elements are repeatable (cf. [27, pp. 387395]). These principles, like other ontological assumptions mentioned in this paper, cannot be justified on the grounds of the natural sciences. The epistemological perspective of physics permits only to specify these assumptions. The acceptance of these assumptions in the investigations of the natural sciences is not a matter of arbitrary choice, since they make possible the scientific research. ${ }^{12}$ These principles must be accepted, if

12 The most recent literature mentions also the principle of the homogeneity of time, that asserts the equivalence of all the temporal moments with regard to the laws 
science is such as it is. The above presuppositions form the contextual framework for the principle of causality that is a verbal expression of the causal relation in general sense; the necessity of this relation is moreover understood recurrent (exceptionless) bringing out the effect under determined conditions. Though the concept of necessity in physics is more general than the concept of causal relation, for the non-causal laws of physics may also be said to be necessary.

It can be stated in view of the above considerations, that the necessity of causal relation in physics is defined with the use of a temporal expression. It is unobjectionable, since for the physicist everything occurs in time. The variables representing time, for the physicist, are always independent. Physical quantities, in mathematical language of physics, are in most cases functions of time that is arithmeticized and diversely measured. The connectives like "earlier," "later," "and then," "and next" in physics are more clear than the modal connectives.

We should also pay some attention to the probabilistic theory of causality. A study of publications of this sort shows us that they analyze mostly the causal relations of everyday life, expressed in the natural language, as for instance in the following proposition: 'A child is afraid of thunder' (cf. [33, pp. 7-11]). Various man's decision-making situations are also being analyzed. Nevertheless, it is difficult to attribute necessity, and other features of the physical causal relation, to the notion of causality used in the analysis of events related to man's conduct.

Another problem arises in connection with the fact that the language of mathematics is the basic language of physics. The problem is whether there exists a special mathematical apparatus to grasp the causal relation. Some authors seem to suggest that differential equations of a special type are such an apparatus (cf. [10, pp. 93-94.]). Bunge is of the opinion that a causal interpretation of the mathematical formula must be something external to this formula. According to the American author, the same mathematical formula may be used to describe causal

of physics. It is debated whether the principle of homogeneity of time applies at the level of the microcosm, macrocosm and megacosm. Its validity is not questioned at the level of microcosm and macrocosm. These realms are investigated by physics that is concerned with various systems. The science concerned with the universe as a whole is called natural cosmology; see [12, pp. 200-201]. It is sometimes stated that the postulate of the invariability of experiences and the invariability of interactions as regards the transitions in time, as each postulate in physics is such that it does not lead to incompatibility with the whole of experience and astronomic observation; see [35, p. 21]. 
and noncausal processes. Z. Zawirski pointed out that the functional formulas deal with the quantitative relations, whereas the cause primarily refers to qualitative relations. According to this Polish philosopher of science, it is possible to apply the concept of function to the causal relation, but this mathematical concept does not exhaust the essence of the causal relation.

Philosophers of science have devoted much attention to the question whether the laws of physics include causal laws. They have comprehensively analyzed the concept of the laws of physics itself. The difficulties which appeared in connection with analyses of this type seem to have resulted mainly from the fact that not enough attention was paid in the literature of philosophy and logic to the problem of language of the natural sciences. We have already mentioned that modern physicists have demanded that the laws of physics that express determined relations be expressed in the artificial language of mathematics. The accepted equations of physical theories give a mathematical image of various types of events (cf. [18, pp. 61-65]). W. Heisenberg believed that the mathematical schemes might capture the nature, but they should be compared with nature, they should be regulated by nature. It is necessary, as the German physicists stressed, to proceed at some point from mathematical language to natural language, if we wish to treat of nature. Physicist is also obliged to explain what actually occurs between experiment and mathematics. For instance, the physicist speaks very precisely about nuclear phenomena when he employs the language of mathematics, but he does not thereby produce an image of the nuclear phenomena. It's the contemporary physicists' responsibility to provide an imaginative language appropriate to the mathematical language of quantum theory. This imaginative language has to be developed in accordance with the basic ontological diagnosis concerning contemporary physics (cf. [18, pp. 71-72]). However, modern physics employs two languages: the mathematical language, which describes concisely the relations occurring in nature, allows to calculate the values of physical quantities, when quantitative information about other quantities is provided. The physicist needs also a language similar to natural language to talk about experiments and communicate the sensually perceptible images of nature. Contemporary physicists by laws mean chiefly quantitative relations. However, the laws of physics may be formulated in a language similar to natural language. Laws formulated in this manner are sometimes called qualitative laws. Krajewski quotes the following 
examples of this type of laws: a spark run through a mixture of oxygen and hydrogen causes explosion; a stone dropped into water produces concentric waves. The former is called a causal law of the executor type, and the latter is called a causal law of the energetic type (cf. [22, pp. 229230]). It is worth adding that each of those laws may be expressed in the form of a conditional. There are also qualitative laws of physics which are not causal laws (cf. [40, vol. 2, p. 229]).

To sum up the remarks of the last section and some remarks from the previous sections we may say that causal laws have a qualitative character and are expressed in the imaginative language (cf. [22, p. 231]). There is no specific mathematical language to express adequately the causal laws. The same causal law may be characterized by various parameters, by various laws formulated in the language of mathematics, that would portray diverse quantitative relations. It must be added that the most fundamental type of the causal relation is the energetic one. ${ }^{13}$ In the course of the physical analysis of the principle of causality the features of each of the most basic causal relations of the energetic type have been specified.

Expression 'principle of determinism' appears in almost every publication on the philosophy of science. Different opinions have been stated on the interrelation between the principle of causality and the principle of determinism (cf. [29, pp. 278-281]). In this paper we advocate the thesis proposed by J. Metallmann, that causal determinism is not equivalent to the general determinism. ${ }^{14}$ This thesis derived from the mutual irreducibility of causal, statistical, and coexistential laws. Accepting Metallmann's thesis leads to the position that the principle of causality is a particular case of the principle of determinism. The principle of determinism states that everything is determined by something in a regular way, wherein both external and internal conditions may be the determining factor. ${ }^{15}$ On the other hand, the formulation of the physical

13 Sometimes other, less fundamental types of the causal relation, are also mentioned; see [22, pp. 132-161].

14 Cf. [27, pp. 262-263] and [6, p. 425]. Gawecki is of a different opinion (cf. [10, p. 32]).

15 Cf. [6, p. 40]. Actually, this principle may be formulated more precisely in physics: if the present state of an isolated physical system and the laws governing it are given, then both past and future states of the system may be determined unambiguously. 
principle of causality, as mentioned earlier, is to characterize each causal relation in the leading discipline of the natural sciences.

To sum up the above remarks concerning the understanding of the cause, effect and causal relation in philosophy - mainly Greek philosophy - and in the natural sciences, we should state that the concepts of cause and effect in contemporary physics are treated as ontological categories. Philosophers of science stress that four categories are to be considered in this context, i.e.: thing, attribute, state, and event. ${ }^{16}$ In physics, both cause and effect should be treated as events which are concrete, individual, unrepeatable, and situated in time and space. The causal relation may occur between two respective events separated in time. They may also be separated in space, but then there must exist a temporally or spatially continual process of transferring energy from the event-cause to the event-effect. However, strictly speaking, we can hardly say that the causal relation occurs between classes of events of the same kind. To the classes of events are applied causal laws. Generally, such laws state that each event of a definite class $X$ produces in determined conditions an event of the class $Y$ (cf. [22, p. 229]). Thus the causal law refers to the class of causes, class of effects and class of conditions. The causal relations are singular cases of the causal law. However, by virtue of the fundamental repeatability of causal relations, our analyses of causal relation do not lose generality. Although the same events are not repeated, occurring events possess desirable characteristics in common (cf. [22, pp. 254-255]).

\section{Part 2. A system of the logic of causal propositions}

\section{Preliminaries}

The question of causality is an ontological question. It is not a logical problem. It concerns quite detailed features of reality and cannot be resolved a priori by the use of logic alone. It may be analyzed by means of logic, but the problem cannot be reduced to logic. Logical questions concern basically the logical structure of propositions that express causal judgments. Bunge wrote in 1959 that no satisfying equivalent of the causal bond had been worked out till then. Amsterdamski, taking a

16 Cf. [22, p. 9]. By event we mean a change of some attribute or attributes of an object or set. 
more general view, noticed in 1983 that we "have no grounds to presume a direct correspondence between the ontological relations and the logical structure of the theorems that are supposed to describe those relations. And indeed, it is difficult to grasp some presupposed ontological relations in logical terms, without employing such terms as necessity or possibility" (cf. [2, p. 53]). As mentioned in the first part of this paper, the laws of science, including the causal laws, and the principle of causality in a language similar to natural, are best expressed in the form of conditional sentences. The causal laws of physics, formulated as conditional propositions of the imaginative language, may also occur as premises or conclusions of some inferences. The question arises as to whether laws and inferences of this type can be expressed in the formal language of the classical propositional calculus? The point is simply whether the conditional occurring in the causal laws of physics and expressed in the imaginative language is effectively a material conditional.

This question was answered negatively in the literature (cf. [7] and $[4$, pp. 72,267$])$. So the problem arise to construct a logical system that would include a conditional adequate for representing the causality in physics. Some attempts have been made to construct such a systems of causal conditional. Most often they were concentrated on constructing the formal characteristic of a connective of conditional that could be used to formalize the causal laws that occur in various sciences and on formalizing the causal expressions which appear in natural language. The most advanced formal system of the logic of causal propositions was constructed by A. W. Burks. ${ }^{17}$ In his logic of causal propositions modal connectives play an essential role.

As mentioned in the first part of the paper, all causal connection in physics are regarded to be necessary. This feature has been variously expressed in the exact language of logic (cf. [31, p. 187] and [5, p. 62]). Burks also took up this issue, however, instead of considering the causal relation to be necessary, he defines logically and causally necessary propositions. The propositional expressions comprising the connective of logical necessity were preliminarily characterized as verifiable or falsifiable without any reference to experience. A more accurate characteristic of the modal concepts was made by means of the concept of logically possible world. The latter is a concept of formal semantics associated with the systems of modal logic. The contemporary systems of modal

17 Cf. [8]. A discussion of this system is included in Kiczuk's paper [20]. 
logic were initially developed syntactically on the basis of rather vague intuitions (cf. [13, pp. 25-30]). Then semantics was adapted, as a highly artificial construction, to corresponding syntactic formulations. The concept of a logically possible worlds plays an important role here. It seems however, that the formal systems in which modal connectives occur must be constructed in such a way that syntactic formulations would be based on well-founded analyses carried out in the philosophy of science, and not on shifting intuitions. One cannot start from artificial construction and proceed to create a formal language to model the causal laws of the various particular sciences. The axioms of the system of the logic of causal propositions must be proved true in the model of a determined causal relation. As mentioned above, the features of this relation may be different or understood in various ways in various particular sciences. Burks had a good intuition that the causal relation should be associated with necessity but it does not mean that this necessity is captured by the Burks' vague logical or, even less clear, connective of causal necessity.

We should note as well that Burks is aware of a temporal aspect of the causal relation (cf. [8, p. 456]). Nevertheless, he believes that the temporal succession of effect after cause may only be expressed by the use of variables ranging over time and that it makes the formulas extremely complex. Though, it seems that the temporal succession may be expressed in a simple way by the connectives of some systems of the logic of temporal propositions. Our observations to this point lead us to conclude that the system of the logic of causal propositions adequate to contemporary physics may be constructed with the use of properly selected connectives of temporal propositions serving to express the necessity of causal relation. Everything indicates that such a system should be based on the classical propositional calculus and on the system ZI of the logic of change that includes appropriate system of the logic of temporal propositions.

It has been shown in the literature on philosophy and logic that the classical propositional logic grew out of the ontological approach to reality. Its validity is guaranteed by the use of truth-functional connectives in the formulation of the basic principles which concerns the whole of reality (cf. [19, p. 54.]). Ontologically oriented authors, as almost all physicists are, may claim that the theorems of the classical propositional logic state the objective relations between various types of entities, as these are grasped in cognition and expressed by means of propositions such relations are considered in all sciences that capture the world in 
its ontological aspect. Those authors use the connectives of classical propositional calculus in a well-grounded way.

The system of the logic of causal propositions CI constructed in this article, will be based on the classical propositional calculus. The objective of developing such a system is to construct a formal language that could serve to formulate precisely various causal relations, considered by natural sciences. This calculus will also provide us with an inferential apparatus to control the non-formal language inferences referring to the causal relations. The specific axioms of the system contain a new connective, called connective of the causal relativistic conditional. All those axioms must be valid in the physical model of the causal relation presented in the first part of the paper and each of them will express a different attribute of this relation. The primitive rules embody intuitively correct and universally accepted rules of inference. The specific connective of CI may be treated as a technical term that will allow to express some thoughts more precisely than when using natural language terms. It could be said also that the language of the systems of logic of causal propositions should facilitate the consolidation, preservation and communication of knowledge concerning the causal relation considered in the natural sciences. Since it is natural to describe events by means of propositions, the system CI will employ only propositional variables ranging over propositions concerning events. ${ }^{18}$

It should be noted that system of the logic of causality may be constructed as to represent the results of the analysis of the causal relation as understood in classical philosophy. This understanding of causal relation was also viewed in the first part of the paper. It was observed there that for the Greek philosophers the cause was always more perfect than the effect. Sometimes in philosophical conceptions, the efficient cause cannot undergo any change (cf. [22, pp. 180-181]). Therefore, it may not be an event of the energetic type. The system of the logic of causal propositions, which takes into account the analyses of causality found in Greek or medieval philosophy, may be radically different from the system CI that deals with the concept of causality assumed in contemporary physics, where the causal relation is regarded as an extremely important type of real relation. There is much to suggest that the formal systems

18 The fact that the basic variable in the system of the logic of causal propositions is the propositional variable representing propositions concerning events points to a certain substantial connection between CI and the ontology of situation that assumes that only propositional language may represent a situation adequately. 
for an adequate representation of causality in classical philosophy will not dispense with Aristotle's syllogistic.

As it has been settled, system CI should be based on the classical propositional calculus. But it needs moreover a connective corresponding to the term time, that would express the temporal succession of effect after cause, as mentioned earlier. Mention has already been made that time plays an extremely important role in modern physics. Symbol ' $\rightsquigarrow$ ' will stand for the connective of causal relativistic conditional. The propositional function ' $p \rightsquigarrow q$ ', containing connective ' $\rightsquigarrow$ ', is to be read: if $p$, then for that reason $q$. Since the systems of the logic of temporal propositions may characterize the formal properties of many connectives associated with the term 'time' and may grasp various properties of time, it is needed to employ in the system of the logic of causal propositions such temporal logic that respects contemporary physics' understanding of time. It seems that von Wright's system "And Then" satisfies this requirement (see [38, pp. 1-11] and [39, pp. 208-221]). The system provides a characteristic of the propositional connective ' $T$ '; its equivalent in natural language is the expression 'and then'. It is worth adding that the system "And Then" assumes an axiom denoting the linearity of time. ${ }^{19}$ It is not assumed in this system that time is discrete, nor it is assumed that time is continuous or dense.

\section{The system "And Then"}

The system "And Then" was developed axiomatically. It is based on the axiomatic system of the classical propositional calculus. "And Then" assumes the following axioms: All classical propositional logic axioms and:

$$
\begin{aligned}
& (p \vee q \top r \vee s) \equiv(p \top r) \vee(p \top s) \vee(q \top r) \vee(q \top s) \\
& (p \top q) \wedge(r \mathrm{\top} s) \equiv(p \wedge r \mathrm{\top} q \wedge s \vee(q \top s) \vee(s \top q)) \\
& p \equiv(p \top q \vee \neg q) \\
& \neg(p \top q \wedge \neg q)
\end{aligned}
$$

19 It must be noted that the natural language connective 'and then' may be axiomatically characterized in different ways. Especially, the second axiom may take on various forms. Instead of the axiom of linearity, there may be assumed the axiom of the circular or branching time. It is to be reminded that previously to the system "And Then", von Wright constructed an axiomatic system of the logic of temporal propositions with the specific connective 'and next' (see [37]). The usage of this connective presupposed a discrete character of the temporal medium. 
In the sequence of symbols: ' $\neg$ ', ' $\wedge$ ', ' $\vee$ ', ' $\rightarrow$ ', ' $\equiv$ ' and ' $T$ ' each preceding symbol binds more strongly (more shortly) than all the symbols following it.

The primitive rules of the system "And Then" are as follows: the rule of substitution, modus ponens, and the rule of extensionality which states that the sides of an equivalence being a theorem are mutually interchangeable in the theorems of the system.

The Finnish logician outlined the proofs of the following theorems:

$$
\begin{gathered}
(p \top q) \vee(p \top \neg q) \vee(\neg p \top q) \vee(\neg p \top \neg q) \\
(p \top p) \vee(p \top \neg p) \vee(\neg p \top p) \vee(\neg p \top \neg p) \\
(p \top q) \rightarrow p \\
\neg(p \wedge \neg p \top q) \\
p \wedge(q \top r) \equiv(p \wedge q \top r) \\
(p \top q) \equiv p \wedge(t \top q) \\
p \wedge(q \top r) \rightarrow(p \top r) \\
(p \top q \wedge r) \rightarrow(p \top q) \\
(p \top q) \wedge(p \top r) \equiv((p \top q) \mathrm{\top} r) \\
((p \top q) \mathrm{\top} r) \equiv((p \mathrm{\top} r) \mathrm{\top} q) \\
(p \mathrm{\top}(q \mathrm{\top} r)) \rightarrow(p \mathrm{\top} r) \\
\neg(t \mathrm{~T} \neg p) \rightarrow(t \mathrm{\top} p)
\end{gathered}
$$

where ' $t$ ' stands for any tautology of the classical propositional logic.

Apart from the theorems quoted by von Wright, there have been proven, among others, the following theorems (cf. [17, pp. 161-162]):

$$
\begin{gathered}
p \rightarrow \neg(\neg p \top q) \\
p \rightarrow \neg(\neg p \top p) \\
p \rightarrow \neg(\neg p \top \neg p) \\
p \rightarrow(p \top p) \vee(p \top \neg p) \\
p \wedge \neg(p \top \neg p) \rightarrow(p \top p) \\
p \rightarrow(\neg(p \top \neg p) \rightarrow(p \top p)) \\
(p \vee q \top r) \equiv(p \top r) \vee(q \top r) \\
(p \top r) \rightarrow(p \vee q \top r) \\
(p \wedge q \top r) \rightarrow(q \top r)
\end{gathered}
$$




\section{The system ZI}

The logico-philosophical literature distinguishes sometimes between the logic of deductive sciences and the logic of empirical sciences. To the latter belongs the logic of physics, understood as a class of formal systems based on the classical propositional calculus and characterizing formally non-extensional connectives that play an important role in the inferences carried out in the imaginative language of contemporary physics. The order in which the various sections of the logic of physics are constructed is not arbitrary. All those systems make considerable use of some of the calculi of the logic of temporal propositions. As we have mentioned, some expressions associated with the term 'time' play an important role in the natural sciences. Among those extremely important are the connectives expressing temporal relations. Everything seems to indicate that an appropriate logic of change, based on the logic of temporal propositions, needs to be developed before the logic of causality. In fact, there is no need to make use of the connectives associated with the term causal relation when constructing the systems of the logic of change, or at least some of them, while it would be difficult to develop a system of logic of causal proposition without at least one connective concerning the term 'change'. Such a connective, characterized formally in the system ZI, is the connective 'there is a change in fact that ...' (cf. [17, pp. 162-173]). This connective is symbolized as ' $Z$ '. It is worth adding that all objects, all events in physics last in time, even if the time of their duration may be different. It must be born in mind when one analyzes respective formulas of system ZI. Here is a characteristic of that system.

Language of the system ZI. The alphabet of the language of the system consists of the following symbols:

1. propositional variables: $p, q, r, p_{1}, q_{1}, r_{1}, \ldots$ (that represent propositions concerning events);

2. truth-functional connectives: $\neg, \wedge, \vee, \rightarrow, \equiv$ (that represent, respectively, the connectives of negation, conjunction, disjunction, material implication and material equivalence);

3. proposition-forming connective of one propositional argument: Z (to be read: "there is a change in fact that ...");

4. proposition-forming connective of two propositional arguments: T (to be read as: "and then");

5. brackets. 
In the sequence of symbols: ' $Z$ ', ' $\neg$ ', ' $\wedge$ ', ' $\vee$ ', ' $\rightarrow$ ', ' $\equiv$ ' and 'T' each preceding symbol binds more strongly (more shortly) than all the symbols which follow it.

Rules of syntax of the language of system ZI. The following expressions are properly well-formed propositional formulas:

1. Each propositional variable is a well-formed propositional formula.

2. A formula composed of the connective ' $Z$ ' and its argument, that is a propositional variable, disjunction or conjunction of propositional variables, or a formula logically equivalent to these in the classical propositional logic. It is assumed that the conjunction of two events describes events which consists on both those events occurring. Such an event is a conjunction of events (sometimes it is called a product of events). The disjunction of two events describes events which consists in occurring of at least of those events. Such an event may be called a disjunction of events (sometimes it is called a sum of events). However, we do not assume that a negation of propositions must describe an event. Such a negation states that the event described by a given proposition does not occur. Or to put it slightly differently, in natural sciences a complement of an event is not necessarily an event. It should be added that treating the complement of event as an event implies the existence of the so-called impossible events (cf. $[5$, pp. 62,65$])$.

3. Formulas composed of the above mentioned and the connective ' $T$ ' according to the syntax of the system "And Then".

4. Formulas composed of the above mentioned formulas and the connectives of propositional calculus.

Axioms of the system ZI. The axioms of the system ZI are all classical propositional logic axioms, all axioms of the system "And Then", and the following formulas:

$$
\begin{gathered}
\mathrm{Z} p \rightarrow p \\
(p \mathrm{\top} \neg p) \rightarrow \mathrm{Z} p \\
\mathrm{Z}(p \wedge q) \rightarrow \mathrm{Z} p \vee \mathrm{Z} q \\
\mathrm{Z} p \wedge q \rightarrow \mathrm{Z}(p \wedge q) \\
\mathrm{Z}(p \vee q) \rightarrow \mathrm{Z} p \vee \mathrm{Z} q \\
\mathrm{Z} p \rightarrow \mathrm{Z}(p \vee q)
\end{gathered}
$$


Primitive rules of inference of ZI. The first rule of substitution allows us to accept correct substitutions of theorems of classical propositional calculus and the system "And Then", as theorems of the system ZI.

The second rule of substitution allows us to accept as theorems correct substitutions of the theorems containing the connective ' $Z$ '. As has been noted, solely propositional variables, their conjunctions or disjunctions and equivalents of those, may be arguments of this connective.

The rule of detachment allows us to accept as theorem of the system the consequent of a conditional that is a theorem of the system, inasmuch as its antecedent is also a theorem.

The rule of extensionality states that if an equivalence is a theorem then its both sides are mutually interchangeable in the theorems of the system.

Examples of theorems of ZI. Following formulas are proven to be theorems of the system ZI (see [17, pp. 165-167]):

$$
\begin{gathered}
p \wedge \neg \mathrm{Z} p \rightarrow(p \mathrm{\top} p) \\
\neg \mathrm{Z} p \wedge \neg \mathrm{Z} q \rightarrow \neg \mathrm{Z}(p \wedge q) \\
p \wedge q \rightarrow(\neg \mathrm{Z}(p \wedge q) \rightarrow \neg \mathrm{Z} p \wedge \neg \mathrm{Z} q) \\
\mathrm{Z}(p \wedge q) \wedge \neg \mathrm{Z} p \rightarrow \mathrm{Z} q \\
(p \top \neg p) \rightarrow \mathrm{Z}(p \wedge q) \\
\mathrm{Z}(p \wedge q \vee r) \rightarrow \mathrm{Z} p \vee \mathrm{Z} q \vee \mathrm{Z} r \\
\mathrm{Z}(p \vee q \vee r) \rightarrow \mathrm{Z} p \vee \mathrm{Z} q \vee \mathrm{Z} r \\
\neg p \rightarrow \neg \mathrm{Z}(p \wedge q) \\
\mathrm{Z} p \rightarrow \neg(\neg p \mathrm{~T} \neg p) \\
\neg p \rightarrow(\neg q \rightarrow \neg \mathrm{Z}(p \vee q)) \\
(\neg p \mathrm{\top} q) \rightarrow \neg \mathrm{Z}(p \wedge q)
\end{gathered}
$$

\section{The system CI}

On the basis of the classical propositional calculus and the systems "And Then" and ZI the axioms may be specified determining the elementary sense of causal relation and characterizing the primitive term of the system of the logic of causal propositions, i.e., the connective occurring in the propositional function 'if $p$ then for that reason $q$ '.

Respective axioms will express, among other things, the attributes of the most fundamental causal relation in physics, that is the relation of the 
energetic type, discussed in the first part of the paper. Each theorem of the logic of causal propositions containing the connective ' $\rightsquigarrow$ ', will refer to the causal relation occurring in determined conditions. Those conditions must coexist with the occurrence of a phenomenon $A$ represented by ' $p$ ', as well as with the occurrence of the event represented by ' $q$ ' in the formula ' $p \rightsquigarrow q$ '. In the theorems of the logic of causality no variable will be introduced to represent propositions concerning conditions.

The language of the system CI. The vocabulary of the language of the system CI consists of all the symbols of the system ZI and also of the proposition-forming connective of two propositional arguments: ' be read "if ..., then for that reason ..."). The following expressions are well formed propositional formulas:

1. All propositional variable.

2. Formulas composed of the connective ' $Z$ ' and its argument according to the rules of syntax of the system $\mathbf{Z I}$.

3. Formulas composed of connective ' $\rightsquigarrow$ ' and its arguments, i.e., two distinct propositional variables or two formulas nonequivalent in classical propositional logic, composed of propositional variables and connectives of conjunction or disjunction. Equivalents of those formulas in classical propositional calculus may also be the arguments of the connective ' $\rightsquigarrow$ '. The left-hand variable in the formula composed of the connective ' $\rightsquigarrow$ ' may be substituted exclusively with the propositions concerning the transition of some amount of energy sufficient to a particular body or a determined separated unity (as for instance an elementary particle) to produce the effect, in a determined temporal interval. ${ }^{20}$

4. formulas composed of the above mentioned formulas and the connective ' $T$ ', according to the rules of syntax of the calculus "And Then";

20 The fact that certain separated unity studied by contemporary physics operates energetically or transfers energy does not mean that a causal relation occurs. By causal relation we intend such relation that employs cause and effect, the influencing one unity by another. As far as the free electrons are concerned, each of them must, by its nature, emit and absorb varying in size photons, that is quanta of the energy of electromagnetic radiation. We are dealing here with the change of energetic type, that is not connected with causal considerations. The logic of change for the philosophy of natural sciences must then be constructed previously to the logic of causal propositions. 
5. expressions composed of the above formulas and the connectives of propositional calculus.

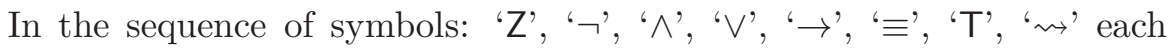
preceding symbol binds more strongly (more shortly) that the symbols following it.

Axioms of the system CI. The axioms of the system CI are: all axioms of classical propositional calculus; all axioms of the system "And Then", all axioms of the system $\mathbf{Z I}$ and the following formulas (A1)-(A7):

$$
(p \rightsquigarrow q) \wedge(q \rightsquigarrow r) \rightarrow(p \rightsquigarrow r)
$$

This axiom expresses the property of transitivity of the causal relation.

$$
(p \rightsquigarrow q) \rightarrow \neg(q \rightsquigarrow p)
$$

The axiom (A2) asserts the asymmetry of a single causal connection, already discussed in the first part of the paper, as if event $x$ brings out event $y$, then event $y$ does not bring out event $x$. For instance, when ball $A$ hits ball $B$, the transfer of energy from ball $A$ will be the cause of corresponding changes in ball $B$, but not vice versa.

It is sometimes emphasized that contemporary science began when people got used to the idea of changing changes (e.g. acceleration, delay in movement), that is events changing in time. It seems that the asymmetry of causal relation is also expressed by the following axiom in which the connective 'there is a change in fact that ...' is used:

$$
(p \rightsquigarrow q) \rightarrow(\mathrm{Z} p \rightarrow(\mathrm{Z} p \mathrm{~T} \mathbf{Z} q))
$$

The transfer or energy from the bearer of the cause to the bearer of the effect substantially determines the asymmetry of the causal relation. Moreover, if a causal relation occurs between two events, then a change of magnitude in the value of the cause brings out a change in the dimensions of the effect. In other words, if $x$ is the cause of $y$ and $x$ undergoes change, then $y$ also undergoes change. Simultaneously, the absence of influences of other bodies, apart from the bearer of the cause, on the bearer of the effect, is assumed.

Given the findings of contemporary physics, concerning absolute precedence of effect over cause (or temporal posteriority of effect to 
cause), the following axiom express an important attribute of the causal relation:

$$
(p \rightsquigarrow q) \rightarrow(p \top q)
$$

Much attention was paid in literature to the question of the necessity of causal relations. It seems to be difficult to characterize this attribute in such a way that it would comprise the necessity of causal relation in all disciplines dealing with causality. For example, admitting the plurality of types of theoretical knowledge, it can be stated that that the necessity of causal relation should be understood differently in classical metaphysics and in the contemporary physics. As we have argued, in the latter case, the necessity of causal relation should be expressed using appropriate temporal terms. Thus in the system of the logic of causal propositions one should assume the following axiom:

$$
(p \rightsquigarrow q) \rightarrow(p \rightarrow q \wedge \neg(t \top \neg q)),
$$

where ' $t$ ' represents any theorem of the classical propositional calculus. ${ }^{21}$ The axiom (A5) is to be understood such that if $p$ is a cause of the fact that $q$, then if the event described by $p$ occurs, now and ever event described by $q$, which is the effect of the event described by $p$, will occur. It may be said that if $p$, then for that reason $q$, then it is and will always be the case that in determined conditions the event of the energetic type, described by proposition $p$, will be the cause of the event described by $q .^{22}$

The connective of relativistic conditional is not a truth-functional connective. However, if two propositions concerning some definite events, being of interests of contemporary physicists, may be joined by the connective of relativistic conditional, then they may be joined by the connective of material conditional. It can be expressed as follows:

$$
(p \rightsquigarrow q) \rightarrow(p \rightarrow q)
$$

21 The very meaning of the axiom (A5) becomes more evident when seen in the light of the specific rule of substitution. See p. 40 on the second rule of substitution.

22 As has been already noted, the necessity of causal relation was expressed formally in many various ways. The axiom (A5) has been formulated - respecting relevant findings of the philosophy of science - by means of an appropriate connective of the logic of temporal propositions. 
In the world of events, that physics is concerned with and that are respectively interrelated causally, the following equivalence will also be true:

$$
(p \rightsquigarrow q) \wedge(p \rightsquigarrow r) \equiv(p \rightsquigarrow(q \wedge r))
$$

The above axioms, expressing the attributes of causal relation, determine also the elementary sense of the causal relation in physics. In the presented approach the cause is treated as an event of the energetic type, which consists in a interaction, in a transfer of energy.

Primitive rules of inference. The first rule of substitution allows us to accept as a theorem of the system CI correct substitution of any theorem of classical propositional calculus and of the system "And Then".

The second rule of substitution allows us to accept as theorems correct substitutions of the theorems containing the connective ' $Z$ '. As has been noted, solely propositional variables, their conjunctions or disjunctions and equivalents of those, may be arguments of this connective.

The third rule of substitution allows us to accept as theorems correct substitutions of theorems containing the binary connective ' $\rightsquigarrow$ '. As has been noted, solely two distinct propositional variables or two formulas nonequivalent in classical propositional logic, composed of propositional variables and connectives of conjunction or disjunction, may be arguments of this connective as well as equivalents of those formulas in classical propositional calculus. The left-hand variable in the formula composed of the connective ' $\rightsquigarrow$ ' may be substituted exclusively with the propositions concerning the transition of some amount of energy sufficient to a particular body or a determined separated unity in the determined temporal interval. Consequently, the right-hand argument of the connective ' $\rightsquigarrow$ ' may be substituted with a proposition concerning the event-effect.

The rule of detachment allows us to accept as theorem of the system the consequent of an conditional that is a theorem of the system, inasmuch as its antecedent is also a theorem.

The rule of extensionality states that if an equivalence is a theorem then its both sides are mutually interchangeable in the theorems of the system.

The consistency of system CI may be proved by the method of interpretation. The connective ' $T$ ' is replaced in the translation by the connective of conjunction; the connective ' $Z$ ' is replaced by the connec- 
tive of assertion, and connective ' $\rightsquigarrow$ ' is to be treated in as a binary falsum connective. After replacements all specific axioms, containing constants ' $T$ ', ' $Z$ ' and ' $\rightsquigarrow$ ' are converted into theorems of classical propositional calculus. Due to consistency of classical propositional calculus, this constitutes the proof of the consistency of the system CI.

Examples of theorems of CI. Here are some of theorems that may be proved in the system $\mathbf{C I}$.

$$
(p \rightsquigarrow q) \wedge \mathrm{Z} p \rightarrow(\mathrm{Z} p \mathrm{~T} \mathrm{Z} q)
$$

Proof:

1. $(p \rightsquigarrow q) \rightarrow(\mathrm{Z} p \rightarrow(\mathrm{Z} p \mathrm{\top} \mathrm{Z} q))$

2. $(p \rightarrow(q \rightarrow r)) \rightarrow(p \wedge q \rightarrow r)$

3. $((p \rightsquigarrow q) \rightarrow(\mathrm{Z} p \rightarrow(\mathrm{Z} p \mathrm{~T} \mathrm{Z} q))) \rightarrow$

$$
((p \rightsquigarrow q) \wedge \mathrm{Z} p \rightarrow(\mathrm{Z} p \top \mathrm{Z} q))
$$

4. $(p \rightsquigarrow q) \wedge \mathrm{Z} p \rightarrow(\mathrm{Z} p \mathrm{~T} \mathrm{Z} q)$

$$
p \wedge(\neg q \vee(t \top \neg q)) \rightarrow \neg(p \rightsquigarrow q)
$$

Theorem (C2) may be easily proved, using (A5) and few laws of classical propositional calculus.

$$
(p \rightsquigarrow r) \rightarrow(p \vee q \top r)
$$

The proof of this theorem employs (A4) and ( $\ddagger)$.

$$
(p \rightsquigarrow q) \rightarrow p
$$

Theorem (C4) may be proved on the basis of (A4) and ( $\star$ ).

$$
(p \rightsquigarrow q) \rightarrow p \wedge(t \top q)
$$

Proof of (C5) employs (A4) and ( $\star \star)$.

$$
(p \rightsquigarrow q) \rightarrow \neg(\neg p \top q)
$$

Theorem (C6) may be proved using $(\mathrm{C} 4),(\dagger)$ and the corresponding theorem of classical propositional calculus.

$$
\neg p \rightarrow \neg(p \rightsquigarrow q)
$$

Theorem (C7) may be proved using (C4) and the law of transposition from classical propositional calculus. 


$$
(\neg p \top q) \rightarrow \neg(p \rightsquigarrow q)
$$

Theorem (C8) may be proved using theorem (C6) and the law of transposition of classical propositional calculus.

$$
\mathrm{Z} p \rightarrow(\neg(\mathrm{Z} p \top \mathrm{Z} q) \rightarrow \neg(p \rightsquigarrow q))
$$

Proof:

1. $(p \rightsquigarrow q) \rightarrow(\mathrm{Z} p \rightarrow(\mathrm{Z} p \mathrm{\top} \mathrm{Z} q))$

2. $\neg(\mathrm{Z} p \rightarrow(\mathrm{Z} p \mathrm{\top} \mathbf{Z} q)) \rightarrow \neg(p \rightsquigarrow q)$

3. $(\mathrm{Z} p \wedge \neg(\mathrm{Z} p \top \mathrm{Z} q)) \rightarrow \neg(p \rightsquigarrow q)$

4. $\mathrm{Z} p \rightarrow(\neg(\mathrm{Z} p \mathrm{TZ} q) \rightarrow \neg(p \rightsquigarrow q))$

3 , the law of exportation

$$
p \rightarrow(\neg q \rightarrow \neg(p \rightsquigarrow q))
$$

The proof of the theorem (C10) requires (A6) and some theorems of classical propositional calculus.

$$
(p \wedge r \rightsquigarrow q) \rightarrow(\neg \mathbf{Z}(p \wedge r) \rightarrow \neg \mathbf{Z} p \wedge \neg \mathbf{Z} r)
$$

The proof of $(\mathrm{C} 11)$ requires $(\mathrm{C} 4)$ and $(\$)$, and respective laws of the classical propositional calculus.

$$
(p \rightsquigarrow q) \rightarrow((p \rightsquigarrow r) \rightarrow \neg(q \wedge r \rightsquigarrow p))
$$

Proof:

1. $(p \rightsquigarrow q) \rightarrow \neg(q \rightsquigarrow p)$

2. $(p \rightsquigarrow q \wedge r) \rightarrow \neg(q \wedge r \rightsquigarrow p)$

3. $(p \rightsquigarrow q) \wedge(p \rightsquigarrow r) \rightarrow \neg(q \wedge r \rightsquigarrow p)$

4. $(p \rightsquigarrow q) \rightarrow((p \rightsquigarrow r) \rightarrow \neg(q \wedge r \rightsquigarrow p)$

3 , law of exportation

$$
(p \rightsquigarrow q) \wedge(q \rightsquigarrow r) \rightarrow(p \top r)
$$

Theorem (C13) may easily be proven using (A1) and (A4).

$$
(p \rightsquigarrow s) \wedge(s \rightsquigarrow q \wedge r) \rightarrow(p \rightsquigarrow q) \wedge(p \rightsquigarrow r)
$$

Proof:

1. $(p \rightsquigarrow s) \wedge(s \rightsquigarrow q \wedge r) \rightarrow(p \rightsquigarrow(q \wedge r))$

2. $(p \rightsquigarrow s) \wedge(s \rightsquigarrow q \wedge r) \rightarrow(p \rightsquigarrow q) \wedge(p \rightsquigarrow r)$

1, (A7), hypothetical syllogism 


$$
(p \rightsquigarrow q) \wedge p \rightarrow(t \top q)
$$

Proof:

1. $(p \rightsquigarrow q) \wedge(p \rightarrow q \wedge \neg(t \top \neg q))$

2. $(p \rightsquigarrow q) \wedge p \rightarrow(q \wedge \neg(t \mathrm{\top} \neg q))$

3. $q \wedge \neg(t \mathrm{~T} \neg q) \rightarrow \neg(t \mathrm{~T} \neg q)$

PC-substitution

4. $\neg(t \mathrm{~T} \neg q) \rightarrow(t \mathrm{~T} q)$

5. $(p \rightsquigarrow q) \wedge p \rightarrow(t \top q)$

$2,3,4$

Summing up all the remarks made in this paper, above presented system of the logic of causal propositions employs the connective of relativistic conditional and connectives of classical propositional calculus as well as some connectives of previously constructed non-classical logics. The choice of those calculi was not accidental. In the course of analyses in the second part of this paper, respecting the statements contained in the first part, which may be called a descriptive semantics of the causal relation, the choice of the logic of temporal propositions and a corresponding system of a logic of change have been justified. Moreover, system ZI was constructed with a view to its possible use in constructing a system of the logic of causal propositions. The connective of relativistic conditional, occurring in the system CI constructed in this paper, and other non-extensional connectives may became technical terms that will allow to express some thoughts more precisely than when using natural language terms. It could be stated that the language of the systems of logic of causal propositions should facilitate the consolidation, preservation and communication of knowledge concerning time, change and causal relation considered in the natural sciences. Moreover, each system of formal logic provides an inferential apparatus and precise tools to control the validity of respective inferences. In the case of system CI these will be tools of controlling inferences carried out mainly in the philosophy of science and natural sciences, especially in physics, as far as its results are communicated in the imaginative language that is close to natural language. (The axioms of the system CI are intended to be true in the model of causal relation appertaining to natural sciences.) In inferences of this sort there often occur connectives related to the terms 'time', 'change', 'causal relation'. These connectives are not extensional. One can hardly prove the correctness of this kind of inferences on the basis of the theorems of the classical logic. All this indicates that the 
system CI, based on the classical logical calculus and providing laws that govern the correct use of the connectives connected with the above mentioned terms, may play a positive role in the indirect justification of theorems in philosophy in a broad sense.

\section{References}

[1] Amsterdamski, S., Między historia a metoda (Between History and Method), Warszawa 1983.

[2] Amsterdamski, S., Nauka a porzadek świata (Science and the Order of the World), Warszawa 1983.

[3] Augustynek, Z., Natura czasu (The Nature of Time), Warszawa 1975.

[4] Borkowski, L., Logika formalna (Formal Logic), Warszawa 1977.

[5] Borkowski, L., "W sprawie intuicyjnej interpretacji logiki trójwartościowej Łukasiewicza" (On the intuitive interpretation of Łukasiewicz's threevalue logic), Roczniki Filozoficzne, 25 (1977).

[6] Bunge, M., Causality, Cambridge 1959.

[7] Burks, A. W., "The logic of causal propositions", Mind, LX (1951), 239: 363-382. DOI: $10.1093 / \mathrm{mind} /$ LX.239.363

[8] Burks, A. W., Chance, Cause, Reason, Chicago-London 1977.

[9] Czeżowski, T., Jak powstało zagadnienie przyczynowości (What is the Origin of the Question of Causality), Wilno 1933.

[10] Gawecki, B., Zagadnienie przyczynowości w fizyce (The Question of Causality in Physics), Warszawa 1969.

[11] Heisenberg, W., Physics and Philosophy, New York 1958.

[12] Heller, M. and J. Życiński, Wszechświat $i$ filozofia (The Universe and Philosophy), Kraków 1980.

[13] Hughes, G. E., and M. J. Cresswell, An Introduction to Modal Logic, London 1974.

[14] Hume, D., A Treatise of the Human Nature, London 1967.

[15] Kamiński, S., "O prawdach koniecznych" (On the necessary truths), Studia Philosophiae Christianae, 4 (1968), 1: 47-63.

[16] Kiczuk, S., "Związek przyczynowy w fizyce współczesnej a logika przyczynowości" (The causal relation in contemporary physics versus the logic of causality), Roczniki Filozoficzne, 25 (1977): 119-121.

[17] Kiczuk, S., "System logiki zmiany", Roczniki Filozoficzne, 33 (1985). The English version: "A system of the logic of change", Logic and Logical Philosophy, 23 (2014), 2: 203-238. DOI: 10.12775/LLP.2014.008

[18] Kiczuk, S., "Język fizyki współczesnej i problem logiki mechaniki kwantowej w ujęciu Wernera Heisenberga" (The language of modern physics and the problem of quantum mechanics according to Werner Heisenberg), Roczniki Filozoficzne, 36 (1988). 
[19] Kiczuk, S., "Zagadnienie obowiązywalnośći klasycznego rachunku zdań" (The question of the validity of the classical propositional calculus), Roczniki Filozoficzne, 36 (1988).

[20] Kiczuk, S., "Artura W. Burksa koncepcja logiki zdań kauzalnych" (Burks' conception of the logic of causal propositions), Roczniki Filozoficzne, 3738 (1989-1990): 311-324.

[21] Kłósak, K., Metafizyczna i fizyczna zasada przyczynowości wobec relacji niedoktadności W. Heisenberga (The Metaphysical and Physical Principle of Causality vs. Heisenberg's Relation of Indeterminacy), Roczniki Filozoficzne, 1 (1948): 198-213.

[22] Krajewski, W., Zwiazek przyczynowy (The Causal Relation), Warszawa 1967.

[23] Krąpiec, M. A., Metafizyka (Metaphysics), Poznań 1966.

[24] Krokiewicz, A. , Pierwsza filozoficzna ksiazka grecka (The First Greek Philosophical Book), Przeglad Filozoficzny, 37 (1934): 46-51.

[25] Krokiewicz, A., "Recenzja: T. Czeżowski, Jak powstało zagadnienie przyczynowości, Wilno 1933" (Review: T. Czeżowski, The Origins of the Question of Causality), Przeglad Filozoficzny, 37 (1934).

[26] Kutz, R., Wstęp do szczególnej teorii względności (An Introduction to the Special Theory of Relativity), Warszawa 1964.

[27] Metallmann, J., Determinizm nauk przyrodniczych (Determinism of the Natural Sciences), Kraków 1934.

[28] Mittelstaedt, P., Philosophische Probleme der modern Physik, Mannheim 1963.

[29] Mazierski, S., Elementy kosmologii filozoficznej i przyrodniczej (Elements of Philosophical and Natural Cosmology), Poznań 1972.

[30] Nagel, E., The Structure of Science: Problems in the Logic of Scientific Explanation, New York \& Burlingame 1961.

[31] Słupecki, J., "Próba intuicyjnej interpretacji logiki trójwartościowej Łukasiewicza" (An attempt at the intuitive interpretation of Łukasiewicz's three-value logic), in: Rozprawy logiczne (Logical Studies), T. Kotarbiński (ed.), Warszawa 1964.

[32] Stępień, A.B., Wprowadzenie do metafizyki (Introduction to Metaphysics), Kraków 1964.

[33] Suppes, P., A Probabilistic Theory of Causality, Amsterdam 1970.

[34] Swieżawski, S., "Kilka uwag o filozofii przyrody w XV-wiecznej Europie lacińskiej" (A few remarks on the philosophy of nature in 15th-century latin Europe), Studia Philosophiae Christianae, 15 (1979).

[35] Szpikowski, S., "Czas w mechanice kwantowej" (Time in Quantum Mechanics), Roczniki Filozoficzne, 25 (1977).

[36] Tatarkiewicz, W., Historia filozofii (History of Philosophy), vol. 1-3, Warszawa 1958. 
[37] von Wright, G.H. "And Next", Acta Philosophica Fennica, 18 (1965): 283-304.

[38] von Wright, G. H. "And Then", Commentationes Physico-Mathematicae. Societas Scientiarum Fennica, 32 (1966), 7.

[39] von Wright, G.H. "Always", Theoria, 34 (1968), 3.

DOI: $10.1111 / \mathrm{j} .1755-2567.1968 . t b 00352 . x$

[40] Wallace, W.A., Causality and Scientific Explanation, vol. 1-2, Michigan 1972.

[41] Wawrzyniak, A., "Koncepcja stosunku przyczynowego według Dawida Hume'a" (The conception of the causal relation according to Hume), Roczniki Filozoficzne, 12 (1964).

[42] Wójcicki, R., Metodologia formalna nauk empirycznych (A Formal Methodology of the Empirical Sciences), Wrocław 1974.

StanisŁaW KicZuK

Faculty of Philosophy

Departament of Logic

The John Paul II Catholic University of Lublin

al. Racławickie 14

20-950 Lublin, Poland 